\title{
Layer-shaped alginate hydrogels enhance the biological performance of human adipose-derived stem cells
}

Bianca Galateanu ${ }^{1}$, Doina Dimonie ${ }^{2}$ Eugeniu Vasile ${ }^{3}$, Sorin Nae ${ }^{4}$, Anisoara Cimpean ${ }^{1 *}$ and Marieta Costache ${ }^{1^{*}}$

\begin{abstract}
Background: The reconstruction of adipose tissue defects is often challenged by the complications that may occur following plastic and reconstructive surgery, including donor-site morbidity, implant migration and foreign body reaction. To overcome these problems, adipose tissue engineering (ATE) using stem cell-based regeneration strategies has been widely explored in the last years. Mounting evidence has shown that adipose-derived stem cells (ADSCs) represent a promising cell source for ATE. In the context of a small number of reports concerning adipose tissue regeneration using three-dimensional (3-D) systems, the present study was designed to evaluate the biological performance of a novel alginate matrix that incorporates human ADSCS (hADSCs).

Results: Culture-expanded cells isolated from the stromal vascular fraction (SVF), corresponding to the third passage which showed the expression of mesenchymal stem cell (MSC) markers, were used in the 3-D culture systems. The latter represented a calcium alginate hydrogel, obtained by the diffusion of calcium gluconate (CGH matrix), and shaped as discoid-thin layer. For comparative purposes, a similar hADSC-laden alginate hydrogel cross-linked with calcium chloride was considered as reference hydrogel (RH matrix). Both hydrogels showed a porous structure under scanning electron microscopy (SEM) and the hADSCs embedded displayed normal spherical morphologies, some of them showing signs of mitosis. More than $85 \%$ of the entrapped cells survived throughout the incubation period of 7 days. The percentage of viable cells was significantly higher within CGH matrix at 2 days post-seeding, and approximately similar within both hydrogels after 7 days of culture. Moreover, both alginate-based hydrogels stimulated cell proliferation. The number of hADSC within hydrogels has increased during the incubation period of 7 days and was higher in the case of CGH matrix. Cells grown under adipogenic conditions for 21 days showed that both analyzed 3-D culture systems support adipogenic differentiation in terms of neutral lipid accumulation and perillipin expression. Furthermore, the cells encapsulated in CGH matrix displayed a more differentiated phenotype.
\end{abstract}

Conclusions: The results of this study suggest that both CGH and RH matrices successfully support the survival and adipogenesis of hADSC. An enhancement of biological performance was detected in the case of CGH matrix, suggesting its promising application in ATE.

Keywords: Adipose tissue engineering, hADSCs, Alginate hydrogel, 3-D culture, Adipogenesis, Viability

\footnotetext{
* Correspondence: anisoara.campean@gmail.com; marietacostache@yahoo.

com

'Department of Biochemistry and Molecular Biology, University of Bucharest,

91-95 Splaiul Independentei, sect 5, Bucharest, Romania

Full list of author information is available at the end of the article
} 


\section{Background}

In the last decade, advances in bioengineering and cell biology of the adipose tissue have been made and new strategies, which effectively reconstruct the soft tissue defects, have been developed [1,2]. Standard approaches on softtissue reconstruction are represented by autologous fat transplantation, alloplastic implants and autologous tissue flaps. However, these approaches have several disadvantages, including donor-site morbidity, implant migration and foreign body reaction. To overcome the limitations of the current restorative techniques, the engineering of the adipose tissue has been proposed as an alternative approach $[3,4]$. Thus, new tissue-engineered systems for the generation of de novo adipose tissue [5,6] are increasingly developing, using the patient's own fat stem cells.

Adipose tissue-derived stem cells (ADSCs) share many similar characteristics to their counterparts in the bone marrow, including the extensive proliferative potential and the capacity to differentiate into a variety of cell types (adipocytes, osteocytes, chondrocytes, myocytes, and neurons), when cultured with the appropriate stimuli [7-11]. As a result of these features, ADSCs can be used for the regeneration and repair of acute and chronically damaged tissues [12]. In addition to the restorative medicine, ADSCs can be used for cosmetic treatments. Currently, there are two possible tissue engineering strategies to induce de novo adipogenesis [13]. One strategy consists in the in vivo induction of adipose tissue from precursor or stem cells originally existing in the body. These cells are able to proliferate and mature into adipocytes by creating a biomimetic environment through site-specific delivery of potent bioactive factors $[14,15]$. The second strategy is to grow in vitro the cells isolated from a patient's own tissue and seed them onto a biocompatible scaffold $[12,16,17]$.

To create adipose tissue-engineered constructs, a diversity of biodegradable natural or synthetic polymer scaffolds has been tested in combination with animal or human adipocyte precursor cells. For instance, such synthetic scaffolds include polylactic-co-glycolic acid (PLGA) $[18,19]$, polyglycolic acid (PGA) [20], and polyethylene terephthalate (PET) [21]. At the same time, a number of biomaterials of natural origin have been investigated for adipose tissue engineering applications, such as collagen sponges [12,22], hyaluronic acid-based scaffolds [23,24], matrigel [25], fibrin [26], and alginate gels [27,28].

The alginate gels cross-linked with calcium ions $(\mathrm{Ca} 2+)$ have been widely used for tissue engineering studies $[29,30]$ due to their high biocompatibility, relatively low cost, reduced immunogenicity, and capacity of forming hydrogels under gentle conditions. Hydrogel-based materials have been frequently used in tissue engineering applications (especially for soft tissues) due to their particular viscoelastic properties, amiability of fabrication into specific shapes, and ability to form biocompatible solid constructs with homogeneous distribution of cells [31]. Their structures provide encapsulated cells with a 3-D environment similar to that of the extracellular matrix (ECM) of soft tissues, allowing a good transfer of gases and nutrients to maintain cell viability [32], adherence, proliferation and differentiation [33]. Furthermore, the alginate may be easily separated from the embedded cells. Thus, exposed to mild chelating agents, alginate can release the entrapped cells, and exposed to a number of ions, including sodium, the alginate may degrade itself [34].

In a previous report it was shown that attachmentdependent cells are unable to specifically interact with alginate, which promotes minimal protein adsorption, probably due to its high hydrophilic nature [32]. This shortcoming was overcome by modifying substrate surface with a peptide containing the Arg-Gly-Asp (RGD) recognition sequence, known for its ability to mimic extracellular matrix molecule binding sites and stimulate cell adhesion to material $[35,36]$.

Numerous studies regarding cellular behavior in or on unmodified alginate hydrogels have been issued. A considerable number of these studies have been devoted to studying the effects of encapsulation of adult MSCs in alginate gels, especially on chondrogenic [37-39] and osteoblastic differentiation [40].

In the context of a small number of reports concerning adipose tissue regeneration using alginate threedimensional (3-D) systems, the present study was designed to evaluate the biological performance of a novel alginate matrix that incorporates human adiposederived stem cells (hADSCs). Therefore, the biological performances of two alginate hydrogel matrices, as temporary physical support for hADSCs, were compared in order to identify an appropriate environment for cell proliferation and adipogenic differentiation. These hydrogels were designed as thin layer disks and prepared by the diffusion of two different cross-linking agents (calcium chloride and calcium gluconate) in cell-loaded alginate solution. The behavior of hADSC cultured under 3-D conditions within alginate hydrogels was analyzed in terms of viability, proliferation, morphology, and adipogenic differentiation.

We found that both calcium gluconate and calcium chloride alginate hydrogels successfully support survival and adipogenic differentiation of hADSC. Moreover, an enhancement of biological performance was detected in the case of CGH matrix, suggesting its promising application in soft tissue engineering.

\section{Methods}

\section{Primary cultures}

The human subcutaneous abdominal white adipose tissue was obtained from moderately overweight women 
undergoing elective liposuction. All the medical procedures were performed in compliance with the Helsinki Declaration, with the approval of the Emergency Hospital for Plastic Surgery and Burns Ethical Committee (reference no. 3076/10.06.2010). All subjects were in good health and provided their written consent before participating to in the study. None of them had diabetes, severe systemic illness, or was taking medications known as impairing the adipose tissue metabolism. Upon sampling, the lipoaspirates (LAs) were immediately processed for obtaining the stromal vascular fraction (SVF).

hADSCs were isolated as described by Gimble et al. [41]. Briefly, LAs were subjected to collagenase digestion and the obtained SVF was centrifuged at $420 \mathrm{~g}$ for $10 \mathrm{~min}$. Then, the pellet was resuspended in growth culture medium (GCM) consisting in Dulbecco's modified Eagle's medium (DMEM, Sigma-Aldrich, Co): Ham-F12 supplemented with $1 \%$ ABAM, $1.2 \mathrm{~g} / \mathrm{L} \quad \mathrm{NaHCO} 3$ (Sigma-Aldrich, Co) and $0.5 \mathrm{mM}$ sodium pyruvate (Sigma-Aldrich, Co) and seeded at an initial density of $1.5 \times 10^{4}$ cells $/ \mathrm{cm}^{2}$ in standard cell culture conditions For the first $24 \mathrm{~h}$, the cells have been maintained in GCM supplemented with 40\% FBS to allow their attachment and then, this medium was changed to GCM containing 10\% FBS.

\section{Subcultivation}

When the cells reached $80 \%$ confluence, they were harvested by trypsinization with $0.25 \%$ trypsin $-0.5 \mathrm{mM}$ EDTA solution (Sigma-Aldrich, Co). After centrifugation, the cellular pellet was suspended in GCM and plated on T75 cell culture flasks (Nunc) at a cell density of $1.5 \times 10^{4}$ cells $/ \mathrm{cm}^{2}$. Due to a decrease in the cell proliferation, the culture was propagated up to eight passages. Cell morphology was analyzed every day by phase contrast microscopy (Nikon Eclipse TS 100).

\section{Characterization of hADSCs cells grown in 2-D culture system \\ Phenotypic characterization}

Immunophenotypic characterization of hADSCs at the third passage was achieved by flow cytometry. We examined the expression of the following cell surface antigens: CD34 (mouse anti-human-PE conjugated monoclonal antibody, code A07776, Beckman Coulter) as a hematopoietic marker and CD44 (mouse anti-human monoclonal antibody, 1:50, code Sc-9960, Santa-Cruz Biotechnology), CD73 (rabbit anti-human polyclonal antibody, 1:50, code Sc-25603, Santa-Cruz Biotechnology), CD90 (mouse antihuman monoclonal antibody, 1:50, code Sc-59396, SantaCruz Biotechnology) and CD105 (mouse anti-human-PE conjugated monoclonal antibody, code A07414, Beckman Coulter) as typical protein markers in MSCs.
Flow cytometric analysis was issued on a FC 500 Cytometer (Beckman Coulter). Approximately 18000 events were acquired on flow cytometer and analyzed using CXP 2.2 software. The third passage cells were trypsinized, washed twice with $1 \%$ bovine serum albumin (BSA, Sigma-Aldrich, Co) solution, and aliquots of $1.4 \times 10^{5}$ cells were incubated at $4^{\circ} \mathrm{C}$ for $30 \mathrm{~min}$ with fluorescent primary antibodies. Upon removal of the excess antibodies by several washes with PBS (Gibco), the samples were subjected to cytometric analysis. Concomitantly, a negative control was prepared by incubating the cells with phycoerythrin (PE) and fluorescein (FITC) conjugated isotype control antibody solution, under the same conditions (IgG1 mouse - PE, code A07796, Beckman Coulter and IgG1 mouse - FITC, code A07795, Beckman Coulter).

\section{3-D cell cultures within alginate hydrogel matrices}

Third passage cells were detached from the monolayer by trypsin-EDTA treatment, centrifuged, counted and mixed with sterile $1.5 \%(\mathrm{w} / \mathrm{v})$ low viscosity sodium alginate in $0.9 \% \mathrm{NaCl}$ at a concentration of $7 \times 10^{5}$ cells $/ \mathrm{ml}$. The cellalginate mixture was distributed into the wells of a 6multiwell culture plate (Nunc) for further flow cytometric studies. For microscopy studies and spectrophotometric MTT (3-(4,5-dimethylthiazol-2-yl)-2,5-diphenyltetrazolium bromide) assay, the cell suspension was distributed into the wells of a 12 multi-well culture plate (Nunc). To produce alginate gel, a sterile disc of Whatmann filter paper, was soaked with the cross-linking agent and placed above the alginate-cell solution. Equal volume of gelling agent was placed above the disk, and plates were incubated for $45-60 \mathrm{~min}$ at $37^{\circ} \mathrm{C}$ in a humidified atmosphere of $5 \% \mathrm{CO}_{2}$. After gelling, the paper disks were removed and the remaining fluid was aspirated. The resulting thin layer alginate hydrogels were sequentially washed with $0.9 \%$ saline solution and GCM, covered with culture medium, and subjected to incubation in standard conditions.

Herein, we used two gelling agents: (1) calcium chloride solution (Sigma-Aldrich, Co) currently used for obtaining cell-laden alginate hydrogels and considered as the reference hydrogel material, and (2) calcium gluconate solution (Zentiva), which is mainly used in preparing the alginate matrix of Drug Delivery Systems. The detailed procedure will be the subject of a patent.

\section{Characterization of hADSCs incorporated in 3-D alginate systems}

Scanning electron microscopy (SEM)

The hADSCs-laden alginate hydrogels, maintained in culture for 2 and 7 days, were washed twice with PBS and fixed for $6 \mathrm{~h}$ at $4^{\circ} \mathrm{C}$ with $2.5 \%$ glutaraldehyde (Sigma-Aldrich, Co) in PBS, containing $0.1 \% \mathrm{CaCl}_{2}$. 
After rinsing with double distilled water, the samples were dried at $20^{\circ} \mathrm{C}$ and 0.1 mbar pressure for 4 hours in a 24-LSC Martin Christ laboratory freeze dryer. Then, the samples were coated with gold and imaged using a FEI Quanta Inspect F with field emission gun (FEG), operating in Scanning Electron Microscopy (SEM) mode. The microscope was driven with an acceleration voltage of $30 \mathrm{kV}$ and a working distance of $10 \mathrm{~mm}$ detecting secondary electrons.

\section{Assessment of cell viability and proliferative activity}

Cell viability within the alginate-based 3-D culture systems was evaluated by flow cytometric determination of live versus dead cells recovered from the hydrogel and stained using Live\&Dead Kit (Invitrogen). This method allows the simultaneous detection of both live and dead cells with calcein acetoxymethyl calcein AM and ethidium bromide dyes provided in the kit. Calcein AM is a non-fluorescent and permeable reagent, which is converted by the intracellular esterases to the intensely green fluorescent calcein (ex/em: $495 \mathrm{~nm} / \sim 635 \mathrm{~nm}$ ). Ethidium bromide enters the cells with damaged membrane, producing a bright red fluorescence when binding to nucleic acids (ex/em: $495 \mathrm{~nm} / \sim 635 \mathrm{~nm}$ ).

Briefly, at 2 and 7 days post-seeding, the two alginatebased hydrogels were first solubilized by incubation for $15 \mathrm{~min}$ at $37^{\circ} \mathrm{C}$ in $94 \mathrm{mM} \mathrm{NaCl}$ solution containing $350 \mathrm{mM}$ sodium citrate (Sigma-Aldrich, Co) and $35 \mathrm{mM}$ MOPS (Sigma-Aldrich, Co). After $10 \mathrm{~min}$ centrifugation at $265 \mathrm{~g}, 1.4 \times 10^{5}$ cells were incubated at room temperature in the dark with calcein AM and ethidium bromide solutions contained in the kit. A mean value of 10.000 events was acquired by FC500 flow cytometer (Beckman Coulter) and analyzed with CXP 2.2 software (Beckman Coulter).

The proliferation capacity of the cells within the alginate hydrogels was assessed by MTT assay at 2 and 7 days post-seeding. Briefly, both $\mathrm{RH}$ and $\mathrm{CGH}$ matrices were incubated for $15 \mathrm{~h}$ in MTT solution $(1 \mathrm{mg} / \mathrm{ml}$ in serum free culture medium) in standard conditions of cultivation. Before dissolving the formazan crystals produced by the metabolically active cells with isopropanol, the images of MTT-stained culture were taken using an Olympus IX71 inverted microscope. Solubilization was followed by spectrophotometric quantification at $550 \mathrm{~nm}$.

\section{Assessment of adipogenic differentiation}

The third passages ADSCs embedded in either $\mathrm{RH}$ or $\mathrm{CGH}$ matrices were analyzed for their capacity to differentiate towards the adipogenic lineage. The adipogenic differentiation was induced by culturing subconfluent cells in a new formula of adipogenic differentiation medium (ADM), consisting in GCM supplemented with an adipogenic cocktail. This experiment was conducted over a 21-day incubation period. The adipogenic differentiation was quantified by the cellular capacity to accumulate intracellular lipids and by perilipin expression level. A detailed description of the ADM medium and of the entire experimental procedure will be provided in a patent application.

The accumulation of cytoplasmic droplets of neutral lipids was assessed by Oil Red $\mathrm{O}$ staining. The alginateembedded cells cultured in 12-well plates were allowed to accommodate for 3-4 days in the new 3-D microenvironment. Subsequently, the GCM was supplemented with the adipogenic cocktail.

The cytoplasmic lipid droplets visualization was issued at different time points, as described by Brandl et al. [15], with modifications. Briefly, the cell-laden alginate hydrogels were washed with PBS and fixed for $8 \mathrm{~h}$ with $4 \%$ PFA. After permeabilization with 2\% BSA/0.1\% Triton X-100 solution, both $\mathrm{CGH}$ and $\mathrm{RH}$ matrices were incubated with Oil Red O $(5 \mathrm{mg} / \mathrm{ml}$ in $60 \%$ isopropanol, diluted 3:2 with tap water) for $24 \mathrm{~h}$ at $4^{\circ} \mathrm{C}$. Upon removal of the Oil Red $\mathrm{O}$ solution, the hydrogels were washed several times to eliminate the traces of staining solution. The assessment of lipid droplets accumulation was revealed by phase contrast microscopy (Olympus IX71) and Cell F Imaging Software (Olympus).

For flow cytometric detection of perilipin at 3, 7, 15 and 21 days after adipogenic induction, 3-D culture systems were first solubilized as previous described. After $10 \mathrm{~min}$ centrifugation at $265 \mathrm{~g}, 1.4 \times 10^{5}$ cells were fixed with $4 \%$ PFA and permeabilized with $2 \%$ BSA/0.1\% Triton X-100 solution. After a short washing step, the cells were incubated overnight with rabbit polyclonal anti-perilipin antibody solution (1:200, Santa-Cruz Biotechnology) and for $30 \mathrm{~min}$ with FITC conjugated goat anti-rabbit IgG1 secondary antibody (1:50, Santa-Cruz Biotechnology). A mean value of 10000 events was acquired and analyzed with CXP 2.2 software (Beckman Coulter). In order to keep the same parameters throughout the entire culture period, the cytometer was calibrated with Flow Check fluorescent beads (Beckman Coulter) before each determination.

\section{Results}

\section{Primary culture and characterization of hADSC in a 2-D culture system}

hADSCs cultures were isolated and purified from human subcutaneous adipose tissue, which was obtained by elective liposuction. The primary culture was obtained by collagenase digestion of the adipose tissue, followed by the seeding of the heterogeneous cell suspension, and subsequent removal of non-adherent cells. As the cells were propagated in monolayer culture, they showed a more uniform fibroblast-like morphology, suggesting the existence of a homogenous ADSC cell population. 


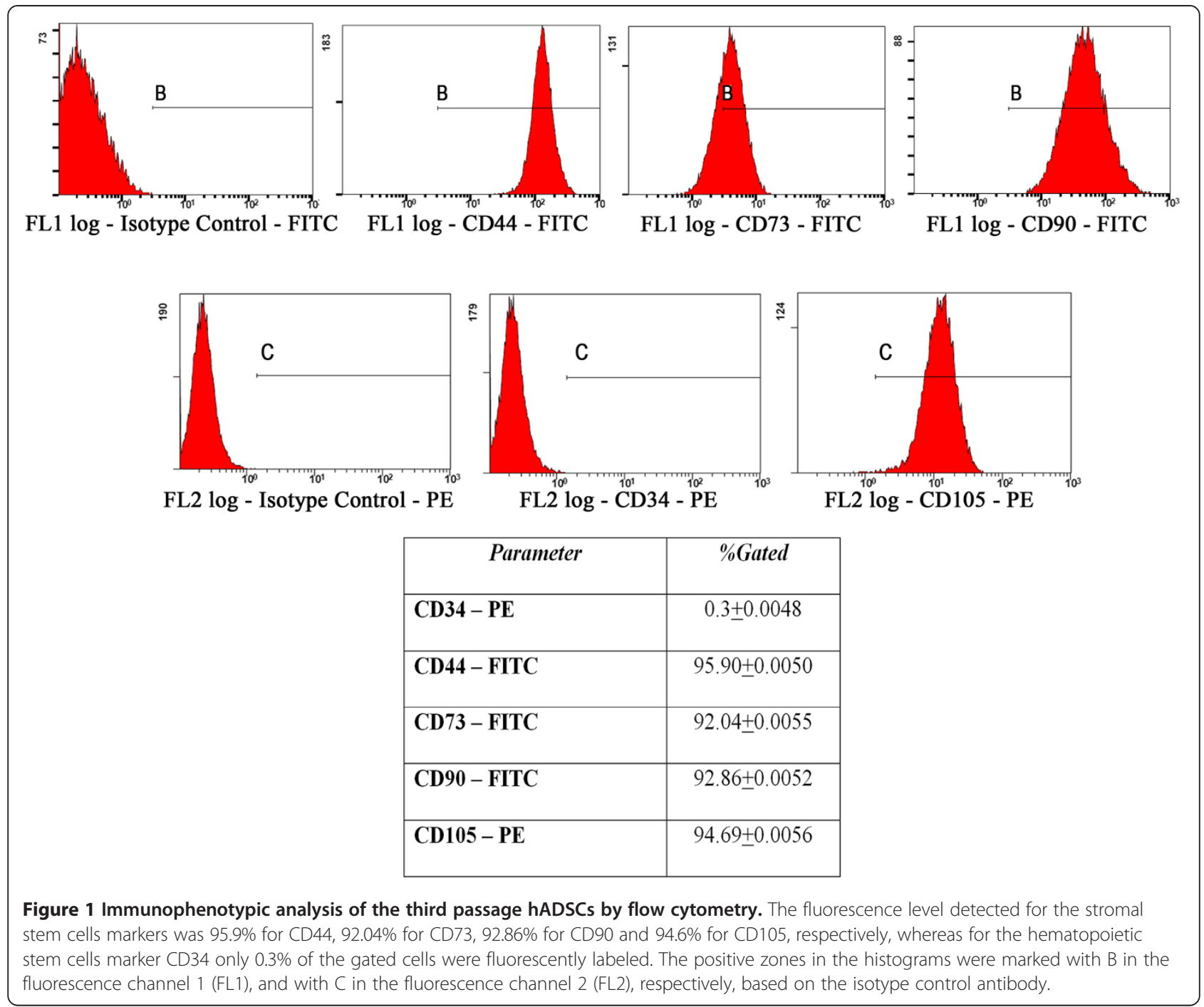

\section{hADSCs cell surface antigen expression}

Given the cell heterogeneity of LAs and of primary culture, serial passages were analyzed for the expression of hADSC-associated markers. The third passage cells were determined as being the most suitable for the incorporation into the alginate matrix (data not shown).

The flow cytometric data revealed that the third passage hADSCs are negative for the hematopoietic marker CD34 and positive for the stromal cell markers CD44, CD73, CD90 and CD105, which are common to human bone marrow-multipotent MSCs (hBM-MSCs) (Figure 1). Thus, more than $90 \%$ of these cells purified by conventional culture methods expressed CD44, CD73, CD90 and CD105 respectively, while only $0.26 \%$ of the cells expressed CD34, which is selectively expressed on hematopoietic progenitor cells and vascular endothelium.

These data suggest that the third passage hADSCs exhibit a MSC origin, and that they are not intermingling with hematopoietic cells. Based on these results, we established that the most suitable hADSCs for incorporation into the alginate matrix were the cells corresponding to the third cell passage.

\section{In vitro behavior of hADSC embedded into alginate hydrogels}

Macroscopic and microscopic evaluation of the cell-laden alginate hydrogels

The hADSC-laden hydrogels were poured into 12 and 6well plates and were constructed as disks of $5 \mathrm{~mm}$ thickness. Throughout the entire culture period these matrices have been stable, have not exhibited any contraction, and could be easily handled. A schematic diagram of the 3-D cell culture system preparation is shown in Figure 2.

The morphology of the cell-laden alginate hydrogels was examined using SEM after 2 and 7 days of culture, respectively. The investigation of the construct surface after 2 days of cultivation revealed the presence of 


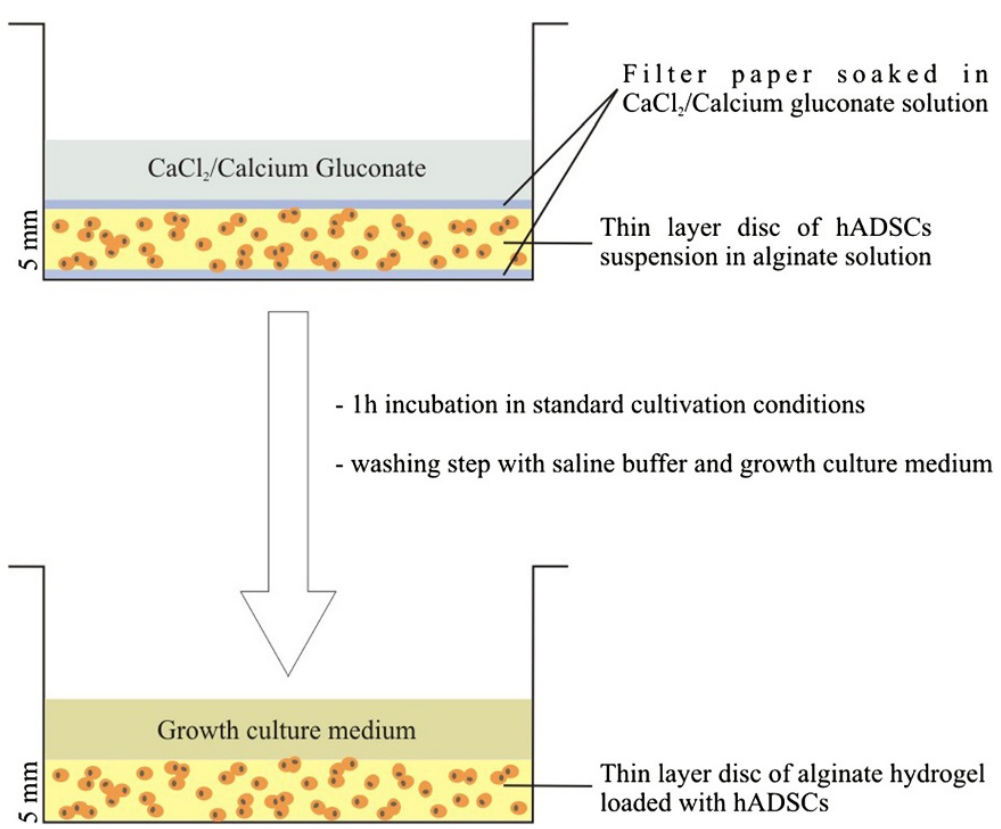

Figure 2 Schematic diagram showing the preparation of the cell-laden layer-shaped alginate hydrogels. STEP 1: A filter paper soaked in the cross-linking agent $\left(\mathrm{CaCl}_{2}\right.$ or calcium gluconate) was placed on the bottom of each well of a 6-well culture plate. The alginate-hADSCS suspension was added above and covered with the second filter paper soaked in the same gelling agent. $\mathrm{CaCl}_{2}$ or calcium gluconate was added on the top of the construct and the plate was incubated for $45-60 \mathrm{~min}$ at $37^{\circ} \mathrm{C}$ in a humidified atmosphere of $5 \% \mathrm{CO}_{2}$; STEP 2: The excess of the cross-linking agent was removed together with both of the filter papers used. The resulting thin layer hydrogel (5 mm thickness) was washed extensively with saline buffer and GCM.

numerous cells in various stages of mitosis, entrapped within the alginate matrix (Figure 3A). SEM images of relevant cross-sections showed that hADSCs were distributed within the pores of the matrix and exhibited a round-shaped morphology due to the lack of interactions between cells and alginate polymer (Figure 3B). The examination of the cross-sections of cell-laden hydrogels at 7 days post-seeding showed that hADSCs remained viable in these matrices, showed signs of mitosis, and seemed to progressively produce and organize their own extracellular matrix (Figure 3C).

\section{hADSCs viability and proliferation in the alginate hydrogels} In order to examine cell survival during culture, the viability of the hADSCs embedded in alginate and recovered by hydrogel solubilization was evaluated at both 2 and 7 days post-seeding, using a LIVE/DEAD assay. Flow cytometric analysis of the labeled cells revealed that at both time points, more than $80 \%$ of the gated cells were positive for the cell viability marker calcein AM, as shown in Figure 4, B4 region of the dot-plots. Two days post-seeding, $19.49 \%$ of hADSCs embedded into $\mathrm{RH}$ alginate matrix and $15.68 \%$ of the cells embedded into CGH matrix were found positive for both calcein AM and Ethidium bromide, suggesting their plasma membrane alteration. Interestingly, after 7 days of culture, the percentage of double-labeled embedded cells decreased to $9.1 \%$ for the $\mathrm{RH}$ matrix and only to $0.66 \%$ for the CGH matrix, respectively (Figure 4 - B3 region of the dot-plots). This could be due to the accommodation of the entrapped cells to the new 3-D culture conditions.

To validate the viability/proliferation rate, MTT assay was employed as a more accurate approach. This test is based on the reduction of a tetrazolium salt solution MTT to purple formazan by metabolic active cells. The precipitated formazan is then solubilized, and the concentration determined by optical density at $550 \mathrm{~nm}$. The result is a sensitive assay with a colorimetric signal proportional to the cell number. Phase contrast micrographs of cell-laden hydrogels after MTT staining revealed the presence of metabolically active cells, at 2 and 7 days of culture, respectively (Figure 5A). A higher number of viable cells converting MTT to formazan crystals were noticed in the CGH matrix as compared to the $\mathrm{RH}$ matrix. This finding is in agreement with the results obtained from the LIVE/DEAD assay.

In addition, a spectrophotometric determination of formazan concentration was issued at the same intervals of time. As shown in Figure 5B, at 2 days of culture, the number of viable metabolically active cells within $\mathrm{CGH}$ matrix was higher by $43.3 \%(\mathrm{p}<0.001)$ than in $\mathrm{RH}$ matrix, while after 7 days of culture this increase was 44.6\% ( $\mathrm{p}<0.001)$. Moreover, hADSCs demonstrated 

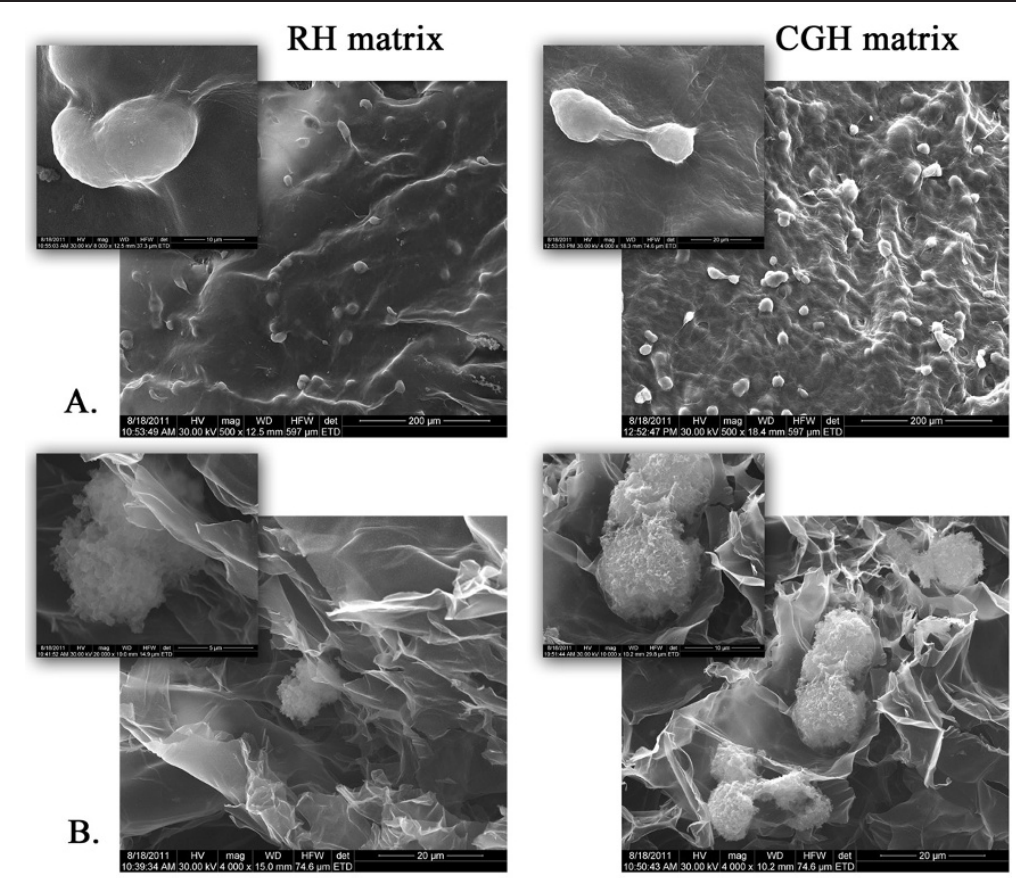

C.
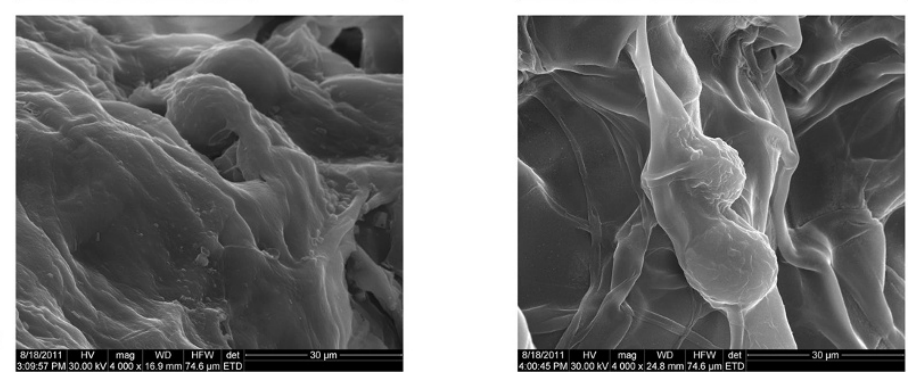

Figure 3 Scanning Electron Microscopy (SEM) micrographs of both 3-D porous cell-laden RH and CGH matrices. A) Surface appearance of RH and CGH matrices after 2 days of culture; B) Cross-sections of the cell-laden 3-D structures at 2 days post-seeding; C) Cross-sections of cellladen hydrogels at 7 days post-seeding.

their ability to proliferate in both analyzed matrices. Indeed, the formazan absorbance measured at $\mathrm{OD}_{550}$ at 7 days post-seeding was approximately $17 \%(\mathrm{p}<0.001)$ higher as compared to the values registered at 2 days post-seeding.

\section{Adipogenic differentiation of hADSCs in the 3-D culture systems}

In order to prove the potential of hADSCs to undergo adipogenic differentiation within alginate hydrogels, GCM was exchanged for the ADM after 3 days of incubation. Intracellular lipid droplet accumulation and perilipin expression have been evaluated at different intervals of time during the incubation period of 21 days for both RH and CGH matrices.

The results of Oil Red staining showed that in the cells embedded in CGH matrix the accumulation of lipids begins at 7 days after adipogenic induction, while for the cells embedded in the RH matrix, a positive staining was observed at 15 days of adipogenic treatment (Figure 6). Furthermore, hADSCs embedded in $\mathrm{CGH}$ matrix were more intensively stained and presented clusters of lipid droplets larger than those seen in the RH matrix. Based on these data it can be concluded that the cells encapsulated in CGH matrix produced more lipid droplets and had a more differentiated phenotype.

In order to prove whether RH and CGH matrices are effective for the adipogenic differentiation, the level of perilipin expression in hADSCs recovered after hydrogel solubilization was detected by flow cytometry.

The expression levels of perilipin have increased significantly during the culture period, reaching a maximum value of $95.12 \%$ for the $\mathrm{RH}$ matrix and $96.59 \%$ for the CGH matrix, respectively, after 21 days of adipogenic induction (Figure 7).

The fluorescence level detected for perilipin expression was increasing in time for both 3-D culture systems. In RH matrix, lower values of fluorescence levels were 


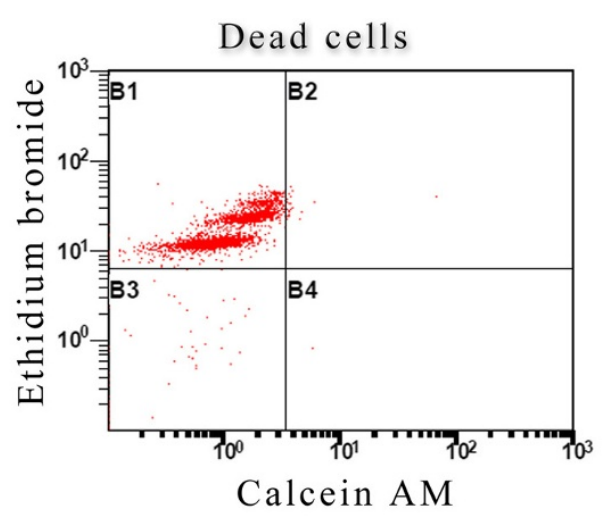

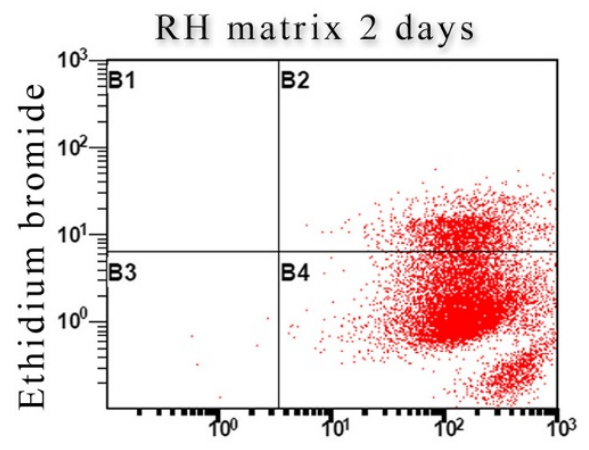

Calcein AM

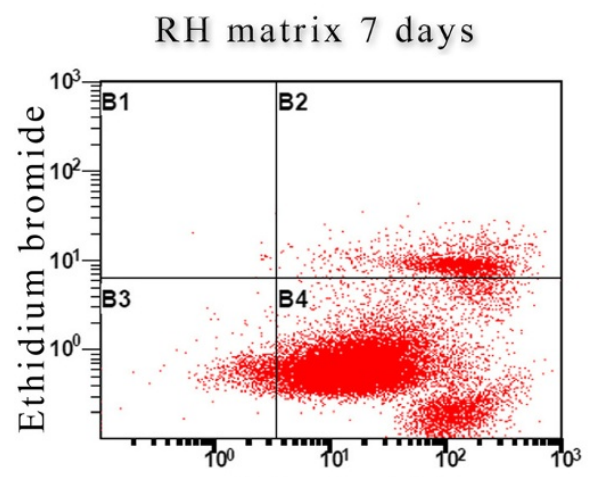

Calcein AM

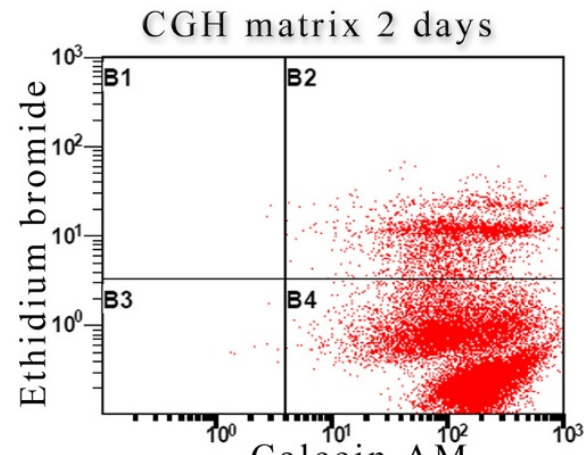

Calcein AM

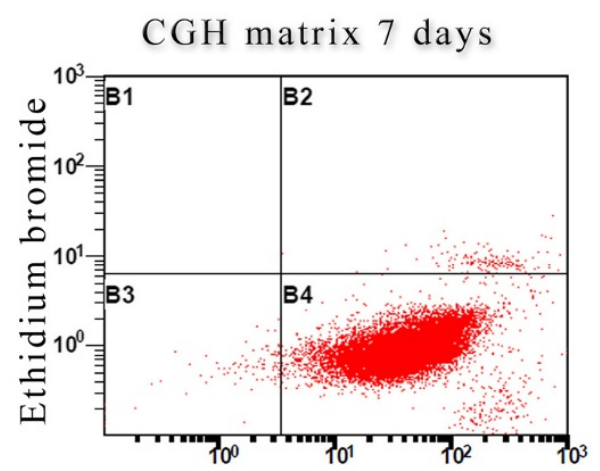

Calcein AM

\begin{tabular}{|c|c|c|c|c|}
\hline & RH 2 days $\%$ & CGH 2 days $\%$ & RH 7 days $\%$ & CGH 7 days $\%$ \\
\hline B2 & $19.49 \pm 0.0016$ & $15.68 \pm 0.0024$ & $9.10 \pm 0.0018$ & $0.66 \pm 0.0020$ \\
\hline B4 & $80.47 \pm 0.0018$ & $84.23 \pm 0.0021$ & $88.94 \pm 0.0031$ & $87.40 \pm 0.0027$ \\
\hline
\end{tabular}

Figure 4 Flow cytometric evaluation of hADSCs viability in both RH and CGH matrices. Fluorescence channel 1 (FL1)/Fluorescence channel 2 (FL2) plots showing Ethidium Bromide positive cells (B1), both Ethidium Bromide and Calcein AM positive cells (B2), unmarked debris (B3) and Calcein AM positive cells (B4).

recorded for 7 and 10 days of adipogenic induction as compared to CGH matrix: $58.27 \%$ and $59.1 \%$ compared to 63.81\% ( $<<0.001)$ and $72.14 \%(\mathrm{p}<0.001)$ respectively. Constant values of perilipin expression were recorded between CGH and RH matrices after 2 weeks of adipogenesis: $75.12 \%$ in $\mathrm{RH}$ matrix compared to $73.22 \%$ in $\mathrm{CGH}$ matrix after 15 days and $95.12 \%$ in $\mathrm{RH}$ compared to 96.59\% in CGH after 21 days of induction.

The results of MTT spectrophotometric assay and flow cytometric data of perilipin expression were statistically analyzed with GraphPrism 3.03. Software using One-way ANOVA with Bonferroni's multiple comparison tests. 

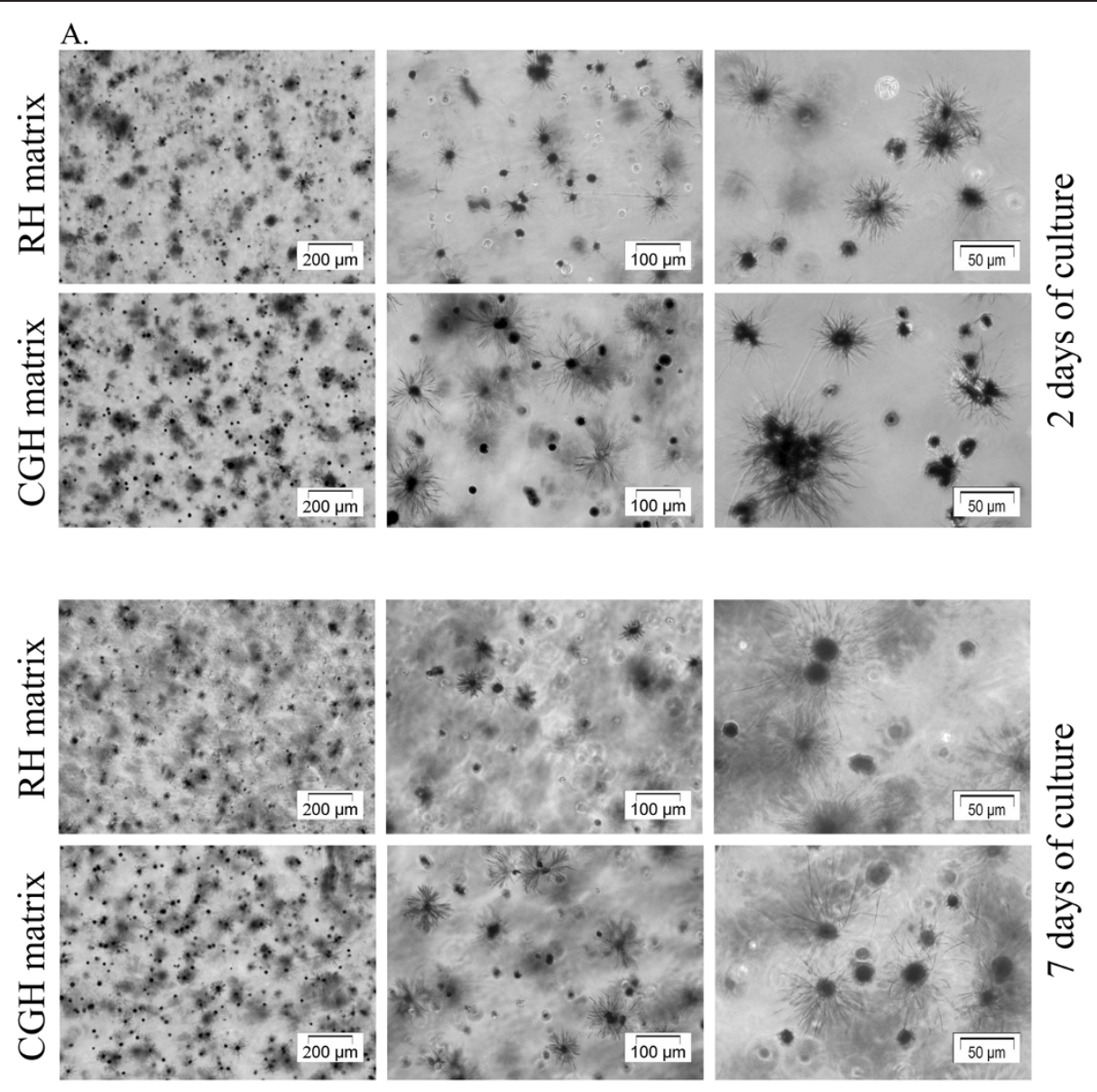

B.

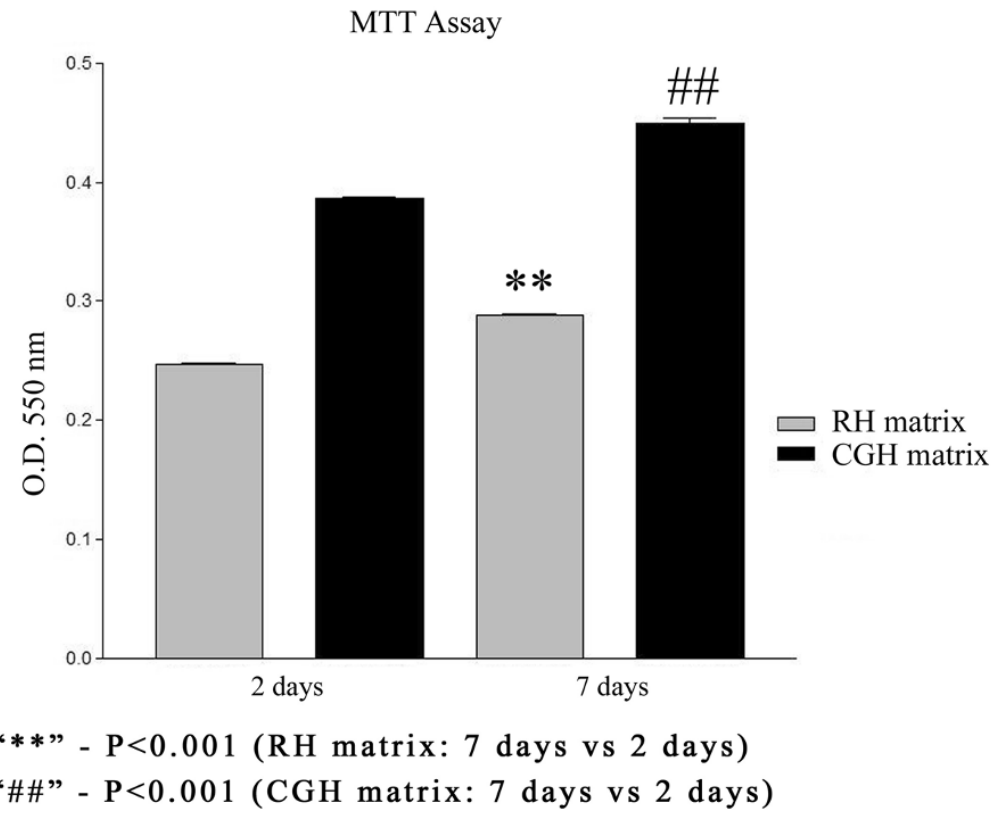

Figure $\mathbf{5}$ (See legend on next page.) 
(See figure on previous page.)

Figure 5 Proliferation potential of hADSCs within RH and CGH matrices. A) Phase contrast micrographs of MTT-stained viable hADSCs embedded in either RH or CGH matrices: UP: Phase contrast micrographs of MTT-stained viable hADSCs embedded in RH and CGH matrices after 2 days of culture showing a higher number of living cells in CGH matrix compared to RH matrix. DOWN: Phase contrast micrographs of MTT-stained viable hADSCs embedded in RH and CGH matrices after 7 days of culture showing an increasing number of living cells in both constructs as a result of cellular proliferation. B) hADSCs proliferation within RH and CGH matrices, measured by formazan absorbance: 2 and 7-days post-seeding. The proliferation rate in CGH matrix at 2 days of culture is $43.3 \%$ higher as compared to the RH matrix. At 7 days post-seeding CGH matrix contains $44.6 \%$ more viable cells than $\mathrm{RH}$ matrix. Both culture systems ensured a proliferation of approximately $17 \%$ at 7 days post-seeding as compared to a culture of 2 days. Results are presented as means $\pm S D(n=3)$.

All results are expressed as means \pm SD (standard deviation) and differences at $\mathrm{p} \leq 0.05$ were considered statistically significant.

\section{Discussion}

Despite intensive work on stem cell-based adipose tissue engineering $[1,2,42]$ much remains to be unraveled regarding the role of the scaffold and culture environment required for the commitment of the undifferentiated cells to the adipogenic differentiation program. Herein, we sought to test a novel cell-laden hydrogel construct that incorporates hADSCs in a calcium alginate gel network. This matrix was shaped as discoid-thin layer obtained by diffusion of calcium gluconate (CGH) and calcium chloride solution (reference hydrogel - RH), respectively, through a filter paper placed above the cell loaded alginate solution. We have chosen the alginate as a cell carrier material since it is a natural polysaccharide abundantly available in nature, which forms hydrogels under relatively mild $\mathrm{pH}$ and temperature conditions. In addition, the alginate is suitable for sterilization and storage for long periods of time prior to its use for cell encapsulation [43]. Furthermore, it is a biodegradable and non-toxic material [32], as the water-soluble alginate chains are excreted by the kidney [44].

Cross-linking of alginate with $\mathrm{CaCl}_{2}$ has been mainly employed to prepare hydrogel-based cell carrier systems shaped as spherical beads [45-47], disks [48] and thin membrane layers [49]. Due to the very rapid binding of $\mathrm{Ca}^{2+}$ to the G-units, it is impossible to obtain a homogeneous gel by simply adding $\mathrm{CaCl}_{2}$ to an alginate solution. Kuo and $\mathrm{Ma}$ [50] described a new method of internal gelation by controlling the gelation rate that uses a less soluble calcium salt $\left(\mathrm{CaCO}_{3}\right)$ and D-glucono- $\delta$-lactone (GDL). The latter was partially hydrolyzed to gluconic acid, which slowly released small amounts of $\mathrm{Ca}^{2+}$ from $\mathrm{CaCO}_{3}$ and allowed the formation of a homogeneous gel. In this study, we developed a procedure to prepare alginate hydrogels that does not involve direct mixing of the alginate solution containing cells with the reticulating agent. We have chosen calcium gluconate as a crosslinking agent because it represents the least toxic form of ionized calcium to cells and tissues and it seems to provide a moderate level of $\mathrm{Ca}^{2+}$. Moreover, this compound was successfully used in preparing the alginate matrix of drug delivery vectors [51-54]. Although the impact of calcium gluconate was not clearly elucidated, Gungor et al. [52] reported that drugs can be released both faster and in a higher amount from the alginate matrices containing calcium gluconate at $\mathrm{pH}$ 7.4. This process was due to the channeling effect of this soluble salt, which increased gel porosity [55].

To gain more insight into the property of calcium gluconate as a cross-linking agent, we analyzed the in vitro behavior of hADSCs into this matrix. The hADSCs were thus embedded into this alginate hydrogel, and their morphology, viability, proliferation capacity and adipogenic differentiation were monitored with respect to a reference hydrogel.

The hADSCs were purified by sequential passage of SVF cells in a culture medium specific for the mesenchymal cell lineage. Thus, a homogenous adherent cell population exhibiting a spindle-shaped fibroblast morphology previously reported for stem cells was noticed starting with the third passage cells [56]. As previously reported, the hADSCs could be readily expanded in culture [3]. They have been shown to exhibit two important properties: (1) proliferation in sufficient amounts to produce cell mass for therapeutic purposes and (2) differentiation into different cell types.

However, the disadvantage of using the ADSCs in tissue engineering is that these cells have a limited capacity for sub-culturing. Based on morphological features and phenotype analysis by flow-cytometry of cultureexpanded cells isolated from the SVF, the cell population corresponding to the third passage, showing the expression of MSC markers, was used in the 3-D culture systems.

To date, there are very few reports on the adipose tissue engineering and soft tissue regeneration using alginate systems as cell carrier materials for hADSCs. For instance, a study issued by Jing et al. [28] demonstrated that mouse pre-differentiated ADSCs embedded into an alginate-based construct had the capacity to form ectopic adipose tissue when implanted into nude mice. To further elucidate the properties of the hADSCs in adipose tissue engineering, we studied the morphology of the hADSCs embedded in both $\mathrm{RH}$ and $\mathrm{CGH}$ matrices. Electron microscope images of the two alginate-based hydrogels showed a porous structure, 


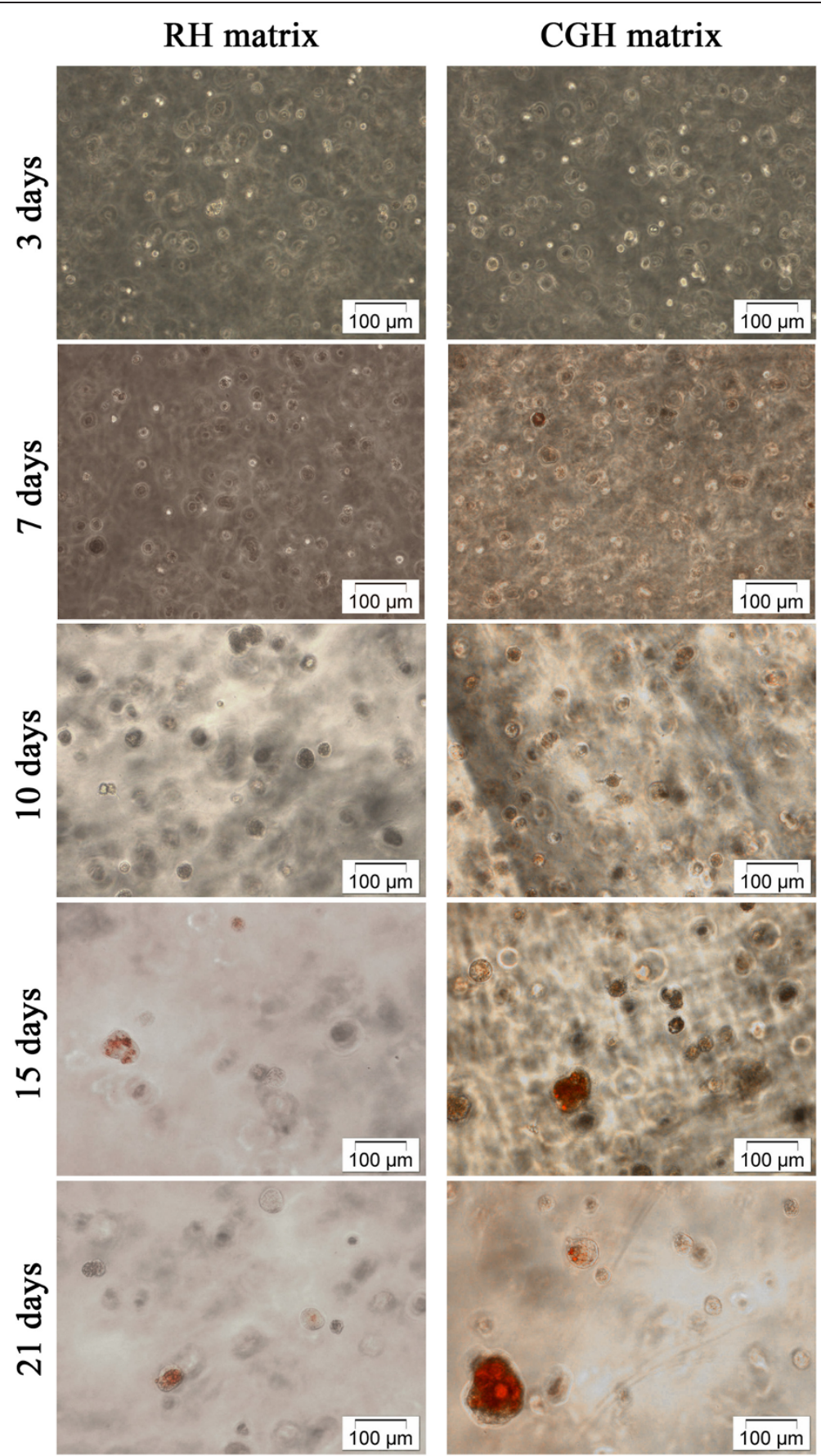

Figure 6 Phase contrast images of hADSCs embedded in RH and CGH and subjected to adipogenesis. Both cell-laden alginate constructs were stained with Oil Red $O$ after 3, 7, 10, 15 and 21 days of adipogenesis, to visualize the size and the amount of cytoplasmic lipid droplets.

whereby the hADSCs display normal spherical morphologies, some of them showing signs of mitosis.

In order to examine cell survival during culture, the viability of the encapsulated hADSCs in the alginate hydrogels was evaluated after 2 and 7 days of culture by a flow cytometry-based LIVE/DEAD assay. At both analyzed time-points, most of the entrapped cells (over 80\%) successfully survived within RH and CGH matrices. Furthermore, the percentage of viable cells was significantly higher within CGH matrix at 2 days post-seeding and approximately similar within both hydrogels after 7 days of culture. These results are in keeping with the observation that the alginate matrices present a structure formed by interconnected pores, which is suitable to accommodate 


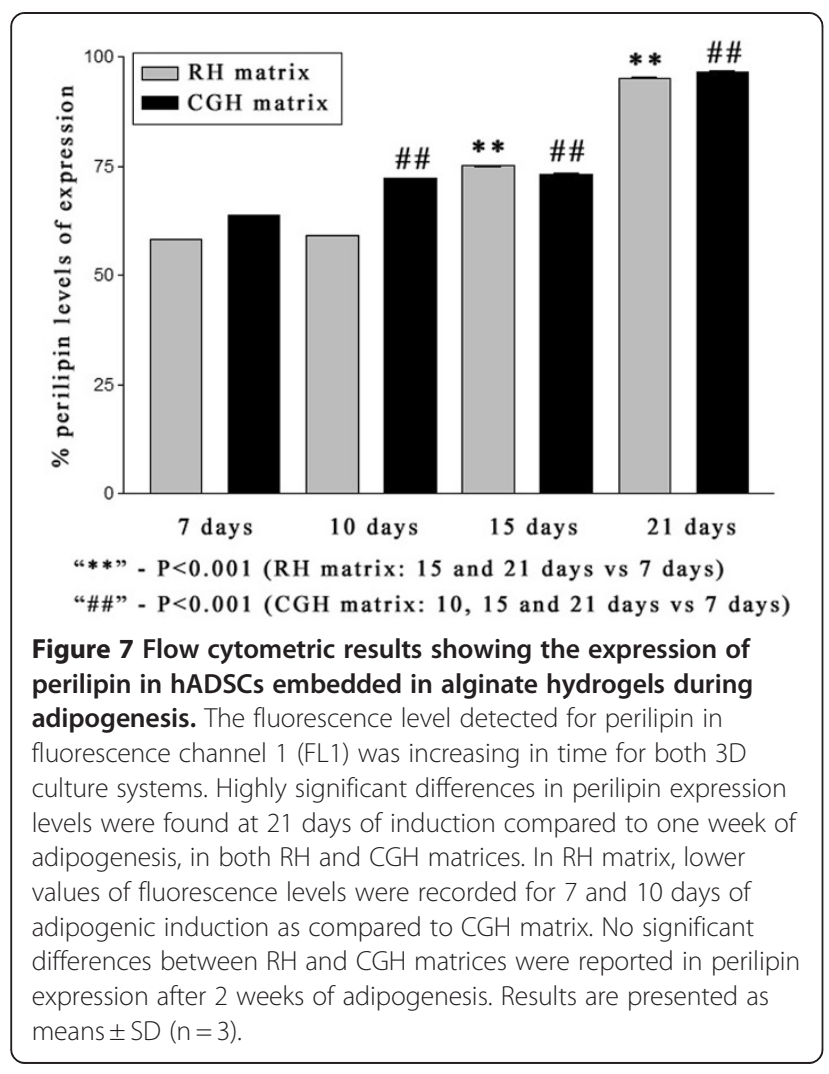

the hADSCs. Furthermore, these matrices successfully supported their viability, nutrient and protein transport.

To get a more complete image on the cell survival and proliferation of hADSC embedded in RH and CGH matrices, microscopic- and spectrophotometric-MTT based assays were issued at the same time intervals. These analyses provided evidence that both alginate-based hydrogels stimulated cell proliferation, the number of hADSCs within hydrogels increasing with the length of the incubation period. This finding is contrary to other studies showing that alginate hydrogels do not allow or inhibit proliferation and growth of several different types of cells when they are either grown on their surface as 2-D monolayer culture or incorporated into the matrix of the gel [57]. Interestingly, in our study, a higher number of metabolically active cells was found within the CGH matrix rather than the RH matrix. Therefore, the growth and metabolic activity of hADSCs seemed to be influenced by the alginate crosslinking agent. The better cell survival and growthsupporting activities of the CGH matrix could be explained by the larger pore sizes than in the case of RH matrix (data not shown). Due to this particular structure, a more efficient transport of oxygen and nutrients may take place in the hydrogel matrix.

To evaluate the effect of calcium gluconate as alginate reticulating agent on adipogenesis, hADSCs encapsulated in alginate hydrogels were cultured with an adipogenic medium up to 21 days. Typical markers of lipid biosynthesis were analyzed. Thus, results of the Oil Red $\mathrm{O}$ staining showed that hADSCs embedded in CGH matrix started the process of neutral lipid accumulation at 7 days post-adipogenic induction, whereas in the cells embedded in $\mathrm{RH}$ matrix, a positive Oil Red O staining was observed after 15 days of adipogenic induction. This result demonstrated that in CGH matrix a greater number of cells have undergone adipogenesis within 21 days of induction, as compared to cells embedded in RH matrix. Flow cytometric detection of perilipin expression also confirmed a more rapid induction of adipogenesis in CGH matrix compared with RH matrix. The delay in the adipogenic induction of hADSC embedded in RH matrix could be explained by the complexity of the effects that $\mathrm{Ca}^{2+}$ exerts on the adipogenesis process [58-60]. Thus, extracellular $\mathrm{Ca}^{2+}$ concentration $\left(\left[\mathrm{Ca}^{2+}\right] \mathrm{e}\right)$ can modulate many aspects of cellular behavior, such as: proliferation, differentiation, survival, and death. Jensen et al. (2004) have shown that the levels of $\left[\mathrm{Ca}^{2+}\right] \mathrm{e}$ are important in regulating adipocyte lipid accumulation. Furthermore, they have demonstrated that increasing intracellular $\mathrm{Ca}$ ions $\left(\left[\mathrm{Ca}^{2+}\right] \mathrm{i}\right)$ in early stages of differentiation suppressed human adipocyte differentiation. Accordingly, the present study demonstrates a faster expression of adipogenic markers (intracellular lipid droplets accumulation and perilipin expression) in CGH matrix compared with the reference hydrogel, probably due to a slower eliberation of the calcium ions. In addition, we cannot rule out a possible influence of $\left[\mathrm{Ca}^{2+}\right]$ on the cell sensitivity to insulin, an adipogenic inductor contained by ADM, as it is largely accepted that increased $\left[\mathrm{Ca}^{2+}\right]$ contributes to insulin resistance [61].

Since perillipin is not expressed before adipogenic differentiation [62], its high expression in the hADSCs embedded in $\mathrm{CGH}$ matrix suggests that calcium gluconate is effective for the adipogenic differentiation of hADSCs in this 3-D culture system.

\section{Conclusions}

A hADSC-laden alginate hydrogel shaped as thin layer disk was developed by diffusion of a new compound, calcium gluconate, within the alginate gel matrix. In addition, we investigated whether calcium gluconate had a positive effect as alginate cross-linking agent on cell viability, proliferation and adipogenic differentiation in comparison with a reference matrix. Our results clearly demonstrate that both alginate microenvironments support hADSCs viability and proliferation. These matrices do not alter the cell morphology and create conditions that are favorable for adipogenic differentiation. Furthermore, an enhancement of all these cellular parameters was found out in the case of alginate hydrogel obtained by using calcium gluconate as reticulating agent, suggesting its promising application in soft tissue engineering. 


\section{Abbreviations}

ADSC: adipose-derived stem cells; ABAM: antibiotic antimycothic; ADM: adipogenic differentiation medium; BSA: bovine serum albumin; CD: cluster of differentiation; $\mathrm{CGH}$ matrix: calcium gluconate hydrogel matrix; FBS: Fetal Bovine Serum; FITC: Fluorescein isothiocyanate; GCM: Growth Culture Medium; GDL: D-glucono- $\delta$-lactone; hADSC: human adipose-derived stem cells; hBM-MSCs: human bone marrow-multipotent mesenchymal stem cells; LAs: Lipoaspirates; MOPS: 3-(N-morpholino)propanesulfonic acid; MSC: Mesenchymal Stem Cells; MTT: 3-(4,5-Dimethylthiazol-2-yl)-2,5diphenyltetrazolium bromide; O.D.: Optic density; PBS: Phosphate Buffer Salt; PE: Phycoeritrine; PET: Polyethylene terephthalate; PGA: polyglycolic acid; PLA: Processed lipoaspirate cells; PLGA: Polylactic-co-glycolic acid; RGD: Arginine-glycine-aspartic acid; RH matrix: Reference Hydrogel matrix; SEM: Scanning Electron Microscopy; SVF: Stromal Vascular Fraction.

\section{Competing interests}

Hereby, we Bianca Galateanu, Anisoara Cimpean and Marieta Costache declare that we are University of Bucharest employees main grant recipient of project PCCE 248/2010 whereby this study was financially supported and whereby this paper fee will be assured in case of acceptance. Therefore we have no competing interests.

Hereby, the undersigned Doina Dimonie I declare that the 3-D system preparation method is protected by a national patent request. Therefore I have no competing interests.

Hereby, Eugeniu Vasile and Sorin Nae declare that we have no competing interests.

\section{Acknowledgements}

This research was supported by Romanian CNCSIS - UEFISCSU, Complex Exploratory Research Project (Grant No.: PCCE248/2010). We thank Prof. Dr. Dana lordachescu (University of Bucharest, Department of Biochemistry and Molecular Biology) for project idea and the invaluable help in conception and design of the experiments and for the initiation of the draft manuscript. We also thank Dr. Mihaela Stefania Diaconu (University of Bucharest, Department of Biochemistry and Molecular Biology) for critical editing of the manuscript and Eng. Chem. Inna Georgeta Trandafir for her involvement in the preparation of the 3-D alginate based constructs.

\section{Author details}

'Department of Biochemistry and Molecular Biology, University of Bucharest, 91-95 Splaiul Independentei, sect 5, Bucharest, Romania. ${ }^{2}$ Research and Development National Institute for Chemistry and Petrochemistry, 202 Splaiul Independentei, sect 6, Bucharest, Romania. ${ }^{3}$ METAV CD, 31 C. A. Rosetti Street, Bucharest, Romania. ${ }^{4}$ Emergency Hospital of Plastic Surgery and Burns, 218 Calea Grivitei Street, sect 1, Bucharest, Romania.

\section{Authors' contributions}

BG carried out the isolation of human adipose-derived stem cells from lipoaspirate and all the procedures performed in the cell culture field. She performed the phase contrast and fluorescence microscopy, the flow cytometry and the spectrophotometric assays and also carried out the statistical analysis. She was involved in the hydrogels design and preparation and helped to draft the manuscript. DD is responsible for the design of the 3-D thin layer alginate hydrogels. EV carried out the SEM assay. SN provided the lipoaspirate in accordance with the EU ethical standards. MC and AC contributed equally to this work. They were responsible for the coordination of the whole study, for the interpretation of the results and for drafting the manuscript. They also assured a good communication between authors. All authors read and approved the final manuscript.

\section{Authors' information}

BG is a PhD Student in the last stage of the internship and researcher in the Department of Biochemistry and Molecular Biology. Her PhD thesis involves the development of new strategies in adipose tissue engineering using precursor cells and natural biocompatible polymers. Her interest in the field of tissue bioengineering was well evaluated at International Congresses. DD is senior researcher at ICECHIM. She has competences in obtaining and studying new eco - friendly polymeric materials for eco - friendly applications. She has a long experience in this field that means papers as main author in ISI coated journals, patents as main author, new products and technologies as project manager.
$\mathrm{EV}$ is PhD Engineer senior researcher with high specialization in microscopy. $\mathrm{SN}$ is a physician in the field of Plastic Surgery and also scientific researcher. He works within the Emergency Hospital for Plastic and Reconstructive Surgery and Burns in Bucharest and he collaborates with numerous aesthetic surgery private clinics.

AC is associate professor in the University of Bucharest and Scientific Researcher in the Department of Biochemistry and Molecular Biology. She attended a post-doc fellowship in Leuven, Belgium and leads research projects concerning the field of tissue bioengineering. MC is full professor at the University of Bucharest, Head of the Department of Biochemistry and Molecular Biology and director of numerous national and international grants. One of the most important research projects led by her is the one financing this study. She obtained her PhD degree in Molecular Biology of the Cell in Paris, France, in 1997.

Received: 6 December 2011 Accepted: 29 June 2012

Published: 29 June 2012

\section{References}

1. Patrick CW Jr: Tissue engineering strategies for adipose tissue repair. Anat Rec 2001, 263(4):361-366

2. Niemelä C, Miettinen S, Sarkanen JR, Ashammakhi N: Adipose Tissue and Adipocyte Differentiation: Molecular and Cellular Aspects and Tissue Engineering Applications. In Topics in Tissue Engineering. Volume 4. Edited by Ashammakhi N, Reis R, Chiellini F.: ; 2008:1-26.

3. Gomillion CT, Burg KJL: Stem cells and adipose tissue engineering. Biomaterials 2006, 27(36):6052-6063.

4. Parker AM, Katz AJ: Adipose-derived stem cells for the regeneration of damaged tissues. Expert Opin Biol Ther 2006, 6(6):567-578.

5. Vermette M, Trottier V, Ménard V, Saint-Pierre L, Roy A, Fradette J: Production of a new tissue-engineered adipose substitute from human adipose-derived stromal cells. Biomaterials 2007, 28(18):2850-2860.

6. Flynn L, Prestwich GD, Semple JL, Woodhouse KA: Adipose tissue engineering with naturally derived scaffolds and adipose-derived stem cells. Biomaterials 2007, 28(26):3834-3842.

7. Gimble JM, Guilak F: Differentiation potential of adipose derived adult stem (ADAS) cells. Curr Top Dev Biol 2003, 58:137-160

8. Hicok KC, Du Laney TV, Zhou YS, Halvorsen YD, Hitt DC, Cooper LF, Gimble JM: Human adipose-derived adult stem cells produce osteoid in vivo. Tissue Eng 2004, 10(3-4):371-380.

9. Skalska U, Burakowski T, Janicka I, Kornatka A, Maldyk P, Maslinski W, Kontny E: Chondrogenic and osteogenic potential of adipose derived stem cells from RA and OA patients. Ann Rheum Dis 2011, 70(Suppl 2):A25.

10. Gwak SJ, Bhang SH, Yang HS, Kim SS, Lee DH, Lee SH, Kim BS: In vitro cardiomyogenic differentiation of adipose-derived stromal cells using transforming growth factor-beta1. Cell Biochem Funct 2009, 27(3):148-154.

11. Safford KM, Hicok KC, Safford SD, Halvorsen YD, Wilkison WO, Gimble JM, Rice HE: Neurogenic differentiation of murine and human adiposederived stromal cells. Biochem Biophys Res Commun 2002, 294(2):371-379.

12. Kimura $Y$, Ozeki M, Inamoto $T$, Tabata $Y$ : Adipose tissue engineering based on human preadipocytes combined with gelatin microspheres containing basic fibroblast growth factor. Biomaterials 2003, 24 (14):2513-2521.

13. Katz AJ, Llull R, Hedrick MH, Futrell JW: Emerging approaches to the tissue engineering of fat. Clin Plast Surg 1999, 26(4):587-603.

14. Kawaguchi N, Toriyama K, Nicodemou-Lena E, Inou K, Torii S, Kitagawa Y: De Novo adipogenesis in mice at the site of injection of basement membrane and basic fibroblast growth factor. Proc Natl Acad Sci USA 1998, 95(3):1062-1066.

15. Hiraoka Y, Yamashiro H, Yasuda K, Kimura Y, Inamoto T, Tabata Y: In situ regeneration of adipose tissue in rat fat pad by combining a collagen scaffold with gelatin microspheres containing basic fibroblast growth factor. Tissue Eng 2006, 12(6):1475-1487.

16. Vashi AV, Abberton KM, Thomas GP, Morrison WA, O'Connor AJ, CooperWhite JJ, Thompson EW: Adipose tissue engineering based on the controlled release of fibroblast growth factor-2 in a collagen matrix. Tissue Eng 2006, 12(11):3035-3043.

17. Girandon L, Kregar-Velikonja N, Bozikov K, Barlik A: In vitro models for adipose tissue engineering with adipose-derived stem cells using different scaffolds of natural origin. Folia Biologica (Praha) 2011, 57 (2):47-56. 
18. Patrick CW, Zheng B, Johnston C, Reece GP: Long-term implantation of preadipocyte-seeded PLGA scaffolds. Tissue Eng 2002, 8(2):283-293.

19. Choi YS, Park SN, Suh H: Adipose tissue engineering using mesenchymal stem cells attached to injectable PLGA spheres. Biomaterials 2005, 26 (29):5855-5863.

20. Fischbach C, Spruss T, Weiser B, Neubauer M, Becker C, Hacker M, Göpferich A, Blunk T: Generation of mature fat pads in vitro and in vivo utilizing 3-D long-term culture of 3 T3-L1 preadipocytes. Exp Cell Res 2004, 300(1):54-64

21. Kang $X$, Xie $Y$, Kniss DA: Adipose tissue model using threedimensional cultivation of preadipocytes seeded onto fibrous polymer scaffolds. Tissue Eng 2005, 11(3-4):458-468.

22. von Heimburg D, Zachariah S, Heschel I, Kuhling H, Schoof H, Hafemann B, Pallua N: Human preadipocytes seeded on freeze-dried collagen scaffolds investigated in vitro and in vivo. Biomaterials 2001, 22(5):429-438.

23. Halbleib M, Skurk T, de Luca C, von Heimburg D, Hauner H: Tissue engineering of white adipose tissue using hyaluronic acid-based scaffolds. I: in vitro differentiation of human adipocyte precursor cells on scaffolds. Biomaterials 2003, 24(18):3125-3132.

24. Stillaert FB, Di Bartolo C, Hunt JA, Rhodes NP, Tognana E, Monstrey S, Blondeel PN: Human clinical experience with adipose precursor cells seeded on hyaluronic acid-based spongy scaffolds. Biomaterials 2008, 29 (29):3953-3959.

25. Walton RL, Beahm EK, Wu L: De novo adipose formation in a vascularized engineered construct. Microsurgery 2004, 24(5):378-384.

26. Cho SW, Kim I, Kim SH, Rhie JW, Choi CY, Kim BS: Enhancement of adipose tissue formation by implantation of adipogenic-differentiated preadipocytes. Biochem Biophys Res Commun 2006, 345(2):588-594.

27. Marler JJ, Guha A, Rowley J, Koka R, Mooney D, Upton J, Vacanti JP: Softtissue augmentation with injectable alginate and syngeneic fibroblasts. Plast Reconstr Surg 2000, 105(6):2049-2058.

28. Jing W, Lin Y, Wu L, Li X, Nie X, Liu L, Tang W, Zheng X, Tian W: Ectopic adipogenesis of preconditioned adipose-derived stromal cells in an alginate system. Cell Tissue Res 2007, 330(3):567-572.

29. Paige KT, Cima LG, Yaremchuk MJ, Schloo BL, Vacanti JP, Vacanti CA: De novo cartilage generation using calcium alginate-chondrocyte constructs. Plast Reconstr Surg 1996, 97(1):168-180.

30. Masuda K, Sah RL, Hejna MJ, Thonar EJ: A novel two-step method for the formation of tissue-engineered cartilage by mature bovine chondrocytes: the alginate-recovered-chondrocyte (ARC) method. $J$ Orthop Res 2003, 21(1):139-148.

31. Ahearne M, Yang Y, El Jaj AJ, Then KY, Liu KK: Characterizing the viscoelastic properties of thin hydrogel-based constructs for tissue engineering applications. J R Soc Interface 2005, 2(5):455-463.

32. Rowley JA, Madlambayan G, Mooney DJ: Alginate hydrogels as synthetic extracellular matrix materials. Biomaterials 1999, 20(1):45-53.

33. Drury $\mathrm{J}$, Mooney DJ: Hydrogels for tissue engineering: scaffold design variables and applications. Biomaterials 2003, 24(24):4337-4351.

34. Ikada Y: Challenges in tissue engineering. J R Soc Interface 2006, 3(10):589601.

35. Rowley JA, Mooney DJ: Alginate type and RGD density control myoblast phenotype. J Biomed Mater Res 2002, 60(2):217-223.

36. Chandler EM, Berglund CM, Lee JS, Polacheck WJ, Gleghorn JP, Kirby BJ, Fischbach C: Stiffness of photocrosslinked RGD- alginate gels regulates adipose progenitor cell behavior. Biotechnol Bioeng 2011, 108(7):1683-1692.

37. Jin XB, Sun YS, Zhang K, Wang J, Ju XD, Lou SQ: Neocartilage formation from predifferentiated human adipose derived stem cells in vivo. Acta Pharmacol Sin 2007, 28(5):663-671.

38. Diekman BO, Rowland CR, Lennon DP, Caplan Al, Guilak F: Chondrogenesis of adult stem cells from adipose tissue and bone marrow: induction by growth factors and cartilage-derived matrix. Tissue Eng Part A 2010, 16 (2):523-533.

39. Hsu SH, Huang TB, Cheng SJ, Weng SY, Tsai CL, Tseng CS, Chen DC, Liu TY, Fu KY, Yen BL: Chondrogenesis from human placenta-derived mesenchymal stem cells in three-dimensional scaffolds for cartilage tissue engineering. Tissue Eng Part A 2011, 17(11-12):1549-1560.

40. Wang L, Shelton RM, Cooper PR, Lawson PR, Triffitt JT, Barralet JE: Evaluation of sodium alginate for bone marrow cell tissue engineering. Biomaterials 2003, 24(20):3475-3481.

41. Gimble JM, Katz AJ, Bunnell BA: Adipose-derived stem cells for regenerative medicine. Circ Res 2007, 100(9):1249-1260.
42. Ogawa R: The importance of adipose-derived stem cells and vascularized tissue regeneration in the field of tissue transplantation. Curr Stem Cell Res Ther 2006, 1(1):13-20

43. d'Ayala GG, Malinconico M, Laurienzo P: Marine derived polysaccharides for biomedical applications: chemical modification approaches. Molecules 2008, 13(9):2069-2106.

44. Al-Shamkhani A, Duncan R: Radioiodination of alginate via covalently-bound tyrosinamide allows for monitoring of its fate in vivo. J Bioact Compat Polym 1995, 10(1):4-13

45. Chubinskaya S, Huch K, Schulze M, Otten L, Aydelotte MB, Cole AA: Human articular chondrocytes cultured in alginate beads maintain their gene expression. Cells Materials 1998, 8:151-160.

46. Li X, Liu T, Song K, Yao L, Ge D, Bao C, Ma X, Cui Z: Culture of neural stem cells in calcium alginate beads. Biotechnol Prog 2006, 22(6):1683-1689.

47. Yamaoka H, Asato H, Ogasawara T, Nishizawa S, Takahashi T, Nakatsuka T, Koshima I, Nakamura K, Kawaguchi H, Chung UI, Takato T, Hoshi K: Cartilage tissue engineering using human auricular chondrocytes embedded in different hydrogel materials. J Biomed Mater Res A 2006, 78(1):1-11.

48. Awad HA, Wickham MQ, Leddy HA, Gimble JM, Guilak F: Chondrogenic differentiation of adipose-derived adult stem cells in agarose, alginate, and gelatin scaffolds. Biomaterials 2004, 25(16):3211-3222.

49. Katsanakis N, Katsivelis A, Kintzios S: Immobilization of electroporated cells for fabrication of cellular biosensors: physiological effects of the shape of calcium alginate matrices and foetal calf serum. Sensors 2009, 9:378-385.

50. Kuo CK, Ma PX: lonically crosslinked alginate hydrogels as scaffold for tissue engineering: part 1. Structure, gelation rate and mechanical properties. Biomaterials 2001, 22(6):511-521.

51. Kuo CK, Ma PX: Maintaining dimensions and mechanical properties of ionically crosslinked alginate hydrogel scaffolds in vitro. J Biomed Mater Res 2008, 84(4):899-907.

52. Güngör S, Yildiz A, Ozsoy Y, Cevher E, Araman A: Investigations on mefenamic acid sustained release tablets with water-insoluble gel. Farmaco 2003, 58(5):397-340.

53. Giunchedi P, Gavini E, Moretti MDL, Pirisino G: Evaluation of alginate compressed matrices as prolonged drug delivery systems. AAPS PharmsciTech 2000, 1(3):31-36.

54. Gilhotra RM, Gilhotra N, Mishra DN: A hydrogel-forming bioadhesive ocular minitablet for the management of microbial Keratitis. Asian $J$ Pharm Sci 2010, 5(1):19-25.

55. Pongjanyakul T, Puttipipatkhachorn S: Modulating drug release and matrix erosion of alginate matrix capsules by microenvironmental interaction with calcium ion. Eur J Pharm Biopharm 2007, 67(1):187-195.

56. Steck E, Bertram H, Abel R, Chen B, Winter A, Richter W: Induction of intervertebral disc-like cells from adult mesenchymal stem cells. Stem Cells 2005, 23(3):403-411

57. Novikova LN, Mosahebi A, Wiberg M, Terenghi G, Kellerth JO, Novikov LN: Alginate hydrogel and matrigel as potential cell carriers for neurotransplantation. J Biomed Mater Res 2006, 77(2):242-252.

58. Hang S, Halvorsen YD, Ellis PN, Wilkison WO, Zemel MB: Role of intracellular calcium in human adipocyte differentiation. Physio/Genomics 2000, 3(2):75-82

59. Jensen B, Farach-Carson MC, Kenaley E, Akanbi KA: High extracellular calcium attenuates adipogenesis in 3 T3-L1 preadipocytes. Exp Cell Res 2004, 301(2):280-292.

60. Draznin B: Cytosolic calcium and insulin resistance. Am J Kidney Dis 1993, 21(3):32-38

61. Fruhbeck G, Gomez-Ambrosi J, Muruzabal FJ, Burrell MA: The adipocyte: a model for integration of endocrine and metabolic signaling in energy metabolism regulation. Am J Physiol Endocrinol Metab 2001, 280(6):827-847.

62. Arimura N, Horiba T, Imagawa M, Shimizu M, Sato R: The peroxisome proliferator-activated receptor $\gamma$ regulates expression of the perilipin gene in adipocytes. J Biol Chem 2004, 279(11):10070-10076.

doi:10.1186/1472-6750-12-35

Cite this article as: Galateanu et al.: Layer-shaped alginate hydrogels enhance the biological performance of human adipose-derived stem cells. BMC Biotechnology 2012 12:35. 